\title{
Clinical Features and Outcome of Strabismus Surgery in Children
}

\author{
Alketa Tandili ${ }^{1}$, Eli Foto ${ }^{2}$ \\ ${ }^{1,2}$ University Hospital Centre "Mother Theresa" Tirana, Albania
}

\begin{abstract}
Pediatric strabismus must be treated early to maximize the potential for binocular vision and decrease the risk of amblyopia. Treatment goals include good vision in each eye and straight eyes. The aim of this study was to describe the outcome of strabismus surgery. The study was conducted at University Hospital Center "Mother Theresa" in Tirana, Albania over the period $2014-2015$ including one hundred patients. The mean age of patients was $11.9( \pm 3.2)$ years, with a range 1 to 22 years. $44 \%$ were females and $56 \%$ males. Abnormal head posture was present in $11 \%$ of patients. Extra ocular movements were full in $65.5 \%$ right eyes and $26.5 \%$ left eyes. Regarding the distribution of patients according to visual acuity, $74 \%$ had visual acuity $6 / 6-6 / 18,16 \%$ had visual acuity of $<6 / 60$ and $10 \%$ had visual acuity of 6/24-6/60 prior to surgery. Surgery in children with esotropia should be performed as early as possible to preserve stereopsis.
\end{abstract}

Keywords: pediatric strabismus, binocular single vision, surgery

\section{Introduction}

Pediatric strabismus must be treated early to maximize the potential for binocular vision and decrease the risk of amblyopia. Treatment goals include good vision in each eye (no amblyopia) and straight eyes (orthotropia). Both conditions are necessary to produce stereopsis, which is a third goal. The eyes of most children are not orthotropic at birth but, rather, are mildly exotropic (deviating outward) $(1,2)$. Neonatal misalignment typically resolves by 3 months, and any strabismus occurring after this age is abnormal. Inputs from the two eyes converge on binocular neurons in the visual cortex, which are thought to be the neural substrate for stereopsis. Maturation of these binocular neurons is dependent on proper ocular alignment early in life $(3,4)$. Childhood strabismus disrupts this process and results in permanent loss of stereopsis if the eyes are not realigned early in development. Among children with infantile esotropia who underwent surgery between 3.5 and 22 months of age (5) (45\% of whom had some postoperative stereopsis), there was a significant correlation between the duration of ocular alignment before the development of esotropia and later stereopsis. Recurrent strabismus is common in children with infantile esotropia. Overcorrection and undercorrection of the original deviation, as well as vertical misalignments, can develop throughout life, and multiple surgeries are often required. In one follow-up study, the risk of recurrent strabismus was more than three times as high in children with no postoperative stereopsis as in those with detectable stereopsis $(6,7)$. It is unclear whether poor or no stereopsis and the high frequency of recurrent strabismus in such children are consequences of early ocular misalignment (and thus potentially modifiable with earlier intervention) or reflect an innate lack of central fusion. The most common type of childhood esotropia is accommodative esotropia, which typically occurs between the ages of 2 and 3 years $(8,9)$. Children with this condition are usually more hypermetropic (farsighted) than are children without the condition and therefore need to accommodate to see clearly. Because accommodation is linked with convergence, focusing drives the eyes inward, producing esotropia. Treatment consists of eyeglasses to correct the full hypermetropic refractive error, which is determined with the use of cyclopentolate eyedrops or another cycloplegic agent to cause temporary paralysis of accommodation $(10,11)$.

\section{Material and Methods}

The study was conducted at University Hospital Center "Mother Theresa" in Tirana, Albania. One hundred patients who underwent squint surger during 2014-2015, either for committant esotropia or exotropia were included in the study.

Detailed history of the patients including duration of deviation, family history of squint, history of ocular trauma, birth history, history of wearing glasses and history of previous ocular surgery were taken. Pre-operative orthoptic evaluation included test for visual acuity, extra ocular movements, Hirschberg test, cover test, prism cover test and Krimsky along with test for binocular single vision and post operative diplopia measurement preoperatively. Similarly, post-operative orthoptic evaluation included measurement of visual acuity, extra ocular movements, cover test, prism cover test and test for binocular single vision. Data pertaining to patient demographics and clinical examination fi ndings were entered in a especially designed performa. Data were analyzed using SPSS. 16 program.

\section{Results and Discussion}

The mean age of patients was $11.9( \pm 3.2)$ years, with a range 1 to 22 years. $44 \%$ were females and $56 \%$ males. Abnormal head posture was present in $11 \%$ of patients. Extra ocular movements were full in $65.5 \%$ right eyes and $26.5 \%$ left eyes. Regarding the distribution of patients according to visual acuity, $74 \%$ had visual acuity $6 / 6-6 / 18,16 \%$ had visual acuity of $<6 / 60$ and $10 \%$ had visual acuity of $6 / 24$ $6 / 60$ prior to surgery. Regarding the distribution of squint, divergent squint was present in $60 \%$, convergent squint in $33 \%$ and intermittent exotropia in $7 \%$ of the patients. $37 \%$ cases had alternate component of strabismus with good visual acuity and $8 \%$ cases had strabismic amblyopia. Anterior segment was abnormal in $14 \%$ right eyes and $17 \%$ 


\section{International Journal of Science and Research (IJSR) \\ ISSN (Online): 2319-7064}

Index Copernicus Value (2013): 6.14 | Impact Factor (2015): 6.391

left eyes. Those having abnormal anterior segment, $12 \%$ had corneal opacity, $7 \%$ were aphakic and $4.5 \%$ had partially absorbed cataract. Fundus evaluation showed abnormal fundus in $12 \%$ right eyes and $16 \%$ left eyes. $88 \%$ underwent recess-resect procedure, $8.5 \%$ underwent bimedial resection and lateral recession, $7 \%$ underwent inferior oblique recession along with recess-resect procedure and $2.5 \%$ underwent single muscle surgery (medial rectus resection) (fig. 1). Pre operative deviation ranged from 25 to 85 prism dioptres $(\Delta)$ with $47.5 \%$ in the group $46-65(\Delta$. After surgery, deviation was $0 \Delta$ in $22.5 \%, 2-8 \Delta$ in $55 \%$ and $10-15 \Delta$ in $22.5 \%$. Binocular single vision was present among $50 \%$ of patients pre-operatively and among $53 \%$ of patients post operatively. Last follow-up time varied from 1 month to 10 months with $47.5 \% 1$ month follow-up. Treatment with eyeglasses within 6 months after the onset of misalignment usually restores proper ocular alignment, with good stereopsis developing in the majority of children. Among children treated with eyeglasses, those with no detectable stereopsis have a much greater likelihood of eventually needing eye-muscle surgery than do those with stereopsis (12-15). Some children with accommodative esotropia remain esotropic when viewing near objects and require bifocals to achieve orthotropia in this setting. Children with esotropia who have no hypermetropia, or whose esotropia cannot be corrected fully with eyeglasses, should undergo strabismus surgery $(16,17)$. Surgery does not improve the esotropia that occurs without eyeglasses but is performed to correct any residual deviation that remains after treatment with eyeglasses. A randomized, multicenter trial showed a slight improvement in postoperative alignment for patients with esotropia who, before surgery, had fusion after a week of wearing eyeglass-mounted prisms to mimic the effect of surgery (prism adaptation), as compared with patients who had surgery without prism adaptation or who did not have fusion with the prisms (18-20). However, the benefit, although statistically significant, was modest, and this technique is not universally used. The aim of this study was to assess pediatric strabismus outcomes and complications in a tertiary hospital. Prospective observational data indicate a significant inverse correlation between the duration of misalignment before surgery and the likelihood of postoperative stereopsis; the data also suggest that the development of stereopsis can be disrupted at least through the age of 4.6 years. The period of susceptibility to the loss of stereopsis probably never completely closes, since adults with acquired strabismus and diplopia risk losing high-grade stereopsis slowly with an increasing duration of misalignment. Intermittent exotropia is one of the most common problems in pediatric ophthalmology. Although no appreciable deviation is present when the patient views near objects, the deviation becomes manifest when the patient views distant objects or is fatigued. A family history of the condition is common, and parents report observing the child habitually closing the nondominant eye when outdoors.

\section{Conclusion}

Surgery in children with esotropia should be performed as early as possible to preserve stereopsis. Strabismus can be present either from birth or acquired during early childhood or adulthood. Strabismus surgery in childhood during the period of cortical plasticity can restore binocular single vision and stereopsis

\section{References}

[1] Dang Y, Racu C, Isenberg SJ. Scleral penetrations and perforations in strabismus surgery and associated risk factors. J AAPOS 2004;8:325-331

[2] Awad AH, Mullaney PB, Al-Hazmi A, et al. Recognized globe perforations during strabismus surgery: incidence, risk factors, and sequelae. J AAPOS 2000;4:150-153

[3] Birch EE, Stager DR Sr, Berry P, Leffler J. Stereopsis and long-term stability of alignment in esotropia. J AAPOS 2004;8:146-150

[4] Fawcett SL, Wang YZ, Birch EE. The critical period for susceptibility of human stereopsis.Invest Ophthalmol Vis Sci 2005;46:521-525

[5] Birch EE. Marshall Parks lecture: binocular sensory outcomes in accommodative ET. J AAPOS 2003;7:369373

[6] Fawcett SL, Stager DR Sr, Felius J. Factors influencing stereoacuity outcomes in adults with acquired strabismus. Am J Ophthalmol 2004;138:931-935

[7] Atkinson J Birch EE, Fawcett SL, Morale SE, Weakley DR Jr, Wheaton DH. Risk factors for accommodative esotropia among hypermetropic children. Invest Ophthalmol Vis Sci2005;46:526-529

[8] Schieman M, Mitchell GL, Cotter S, et al. A randomized clinical trial of treatments for convergence insufficiency in children. Arch Ophthalmol 2005;123:14-24

[9] Kushner BJ. The treatment of convergence insufficiency. Arch Ophthalmol 2005;123:100-101

[10]Repka MX, Beck RW, Holmes JM, et al. A randomized trial of patching regimens for treatment of moderate amblyopia in children. Arch Ophthalmol 2003;121:603611

[11] Holmes JM, Kraker RT, Beck RW, et al. A randomized trial of patching regimens for treatment of severe amblyopia in children. Ophthalmology 2003;110:20752087

[12] Repka MX, Cotter SA, Beck RW, et al. A randomized trial of atropine regimens for treatment of moderate amblyopia in children. Ophthalmology 2004;111:20762085

[13] Wu C, Hunter DG. Amblyopia: diagnostic and therapeutic options. Am J Ophthalmol2006;141:175184

[14]Holmes JM, Clarke MP. Amblyopia. Lancet 2006;367:1343-1351

[15] Mets MB, Beauchamp C, Haldi BA. Binocularity following surgical correction of strabismus in adult. Trans Am Ophthalmol Soc. 2003;101:201- 7

[16] Garabaghi D, Azadeh M. Binocular vision and stereopsis following delayed strabismus surgery. Iranian Journal of Ophthalmology. 2006;19(2):46- 50.

[17] Holmes JM, Beck RW, Kraker RT, et al. Risk of amblyopia recurrence after cessation of treatment. J AAPOS 2004;8:420-428

[18] Paula M. Edelman, C.O. Functional benefi t of adult strabismus surgery. Amer. Orthoptic J. 2010;(60):143-7 


\section{International Journal of Science and Research (IJSR) \\ ISSN (Online): 2319-7064}

Index Copernicus Value (2013): 6.14 | Impact Factor (2015): 6.391

[19] Thomas S., Guha S. Large angle strabismus: Can a single surgical procedure achieve a successful outcome? Strabismu. 2010;18(4):129-36. dx.doi.org/10.3109/09273972.2010.525778

[20] Acun Gezer, Fazil Sezen, Nail Sahri, Nilufer Gozum. Factors infl uencing the outcome of strabismus surgery in patients with exotropia. JAAPOS. 2004;8(1):56-60. ttp:// dx.doi.org/10.1016/j.jaapos.2003.08.006

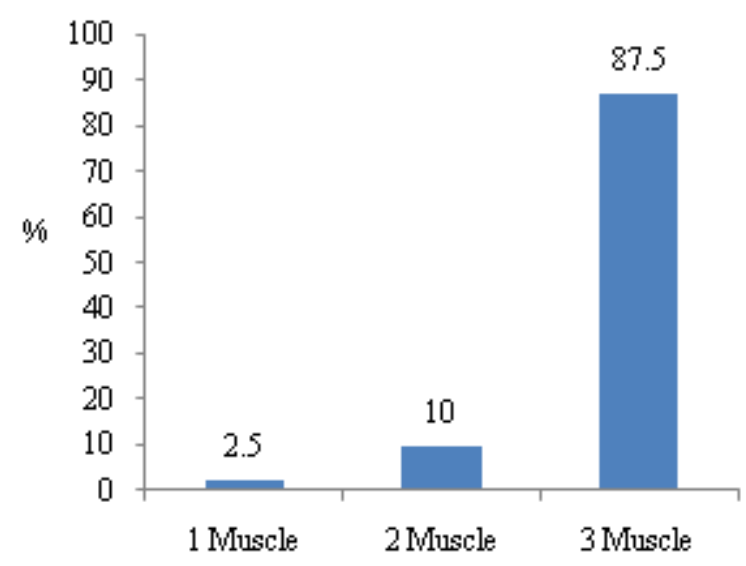

Figure 1: Distribution of muscle surgery 